\title{
Positive lightning flashes recorded on the Säntis tower from May 2010 to January 2012
}

\author{
Carlos Romero, ${ }^{1}$ Farhad Rachidi, ${ }^{1}$ Marcos Rubinstein, ${ }^{2}$ Mario Paolone, ${ }^{3}$ \\ Vladimir A. Rakov, ${ }^{4}$ and Davide Pavanello ${ }^{5}$ \\ Received 1 June 2013; revised 13 October 2013; accepted 3 November 2013; published 5 December 2013.
}

[1] We analyze currents of 30 positive flashes recorded on the Säntis tower, Switzerland, from May 2010 to January 2012. The currents were classified into two types. Type 1 events exhibit a large, unipolar main pulse with a risetime of tens of microseconds, followed by subsidiary peaks separated by millisecond-scale intervals. The main pulse in three flashes was preceded by a slowly rising ramp lasting several milliseconds and was followed by a relatively steady current with superimposed positive and negative pulses, constituting the first direct evidence of $M$ components of both polarities. In four of the five type 1 flashes, the main current was preceded by pulse bursts, presumably due to attempted negative leaders. Type 2 events are characterized by a millisecond-scale waveform with large, oscillatory pulse trains on its rising portion. These pulse trains are inferred to be due to upward negative stepped leaders. Peak currents of type 2 flashes are associated with the fast pulses. Our positive flashes of both types have a median peak current of $11.1 \mathrm{kA}$ and a median duration of $80 \mathrm{~ms}$, consistent with data recorded in Austria. Our measured median transferred charges are about 6 times larger than those at Switzerland's Monte San Salvatore and in Japan and about 3 times larger than in Austria. Eight type 2 flashes in our data set transported over 500 $\mathrm{C}$ of positive charge to ground. Our five type 1 events appear to be similar (except for the pulse duration) to their counterparts examined by Berger et al. (1975). Our type 2 events are "classical" upward flashes.

Citation: Romero, C., F. Rachidi, M. Rubinstein, M. Paolone, V. A. Rakov, and D. Pavanello (2013), Positive lightning flashes recorded on the Säntis tower from May 2010 to January 2012, J. Geophys. Res. Atmos., 118, 12,879-12,892, doi:10.1002/2013JD020242.

\section{Introduction}

[2] This paper presents an analysis of measured current waveforms associated with positive flashes recorded on the Säntis tower from May 2010 through January 2012. Preliminary analyses of the data were presented in Romero et al. [2011, 2012c]. The overall number of recorded flashes in the considered period was 200 , of which 30 were of positive polarity and 3 were classified as bipolar.

[3] Although the incidence of positive lightning flashes is of the order of 10 times lower than that of negative flashes, they are of great interest to the scientific and engineering

\footnotetext{
${ }^{1}$ Electromagnetic Compatibility Laboratory, Swiss Federal Institute of Technology (EPFL), Lausanne, Switzerland.

${ }^{2}$ University of Applied Sciences of Western Switzerland, Yverdon-lesBains, Switzerland.

${ }^{3}$ Distributed Energy Systems Laboratory, Swiss Federal Institute of Technology (EPFL), Lausanne, Switzerland.

${ }^{4}$ Department of Electrical and Computer Engineering, University of Florida, Gainesville, Florida, USA.

${ }^{5}$ University of Applied Sciences of Western Switzerland (HES-SO), Sion, Switzerland.

Corresponding author: M. Rubinstein, University of Applied Sciences of Western Switzerland, 1400 Yverdon-les-Bains, Vaud, CH-1400, Switzerland. (marcos.rubinstein@heig-vd.ch)

(C)2013. American Geophysical Union. All Rights Reserved. 2169-897X/13/10.1002/2013JD020242
}

communities for the following reasons: First, compared to negative lightning, positive flashes exhibit higher peak currents and they lower more charge to the ground [Rakov, 2003]. Positive lightning is therefore a special concern for engineers responsible for the protection of wind turbines and telecommunication towers. Second, the complex structure of the electromagnetic fields radiated by positive lightning can make these flashes difficult to detect and prone to misclassification by lightning location systems. Third, positive lightning has been shown to be associated with the initiation of sprites [e.g., Saba et al., 2010; Yashunin et al., 2007], hence its importance in the study of transient luminous events in the middle atmosphere.

[4] Furthermore, experimental data on positive lightning are scarce and often controversial [Rakov, 2003].

[5] Only a few studies have been published presenting directly measured currents from positive flashes [e.g., Berger et al., 1975; Diendorfer et al., 2006; Goto and Narita, 1995; Wada et al., 1996]. Most other positive lightning studies are based on distant electric field measurements [e.g., Cooray and Pérez, 1994; Fuquay, 1982; Ishii et al., 1998; Nag and Rakov, 2012], high-speed video optical observations [e.g., Campos et al., 2009; Fleenor et al., 2009; Saba et al., 2009, 2008, 2010], or on a combination of remote field and optical measurements [e.g., Kong et al., 2008]. 


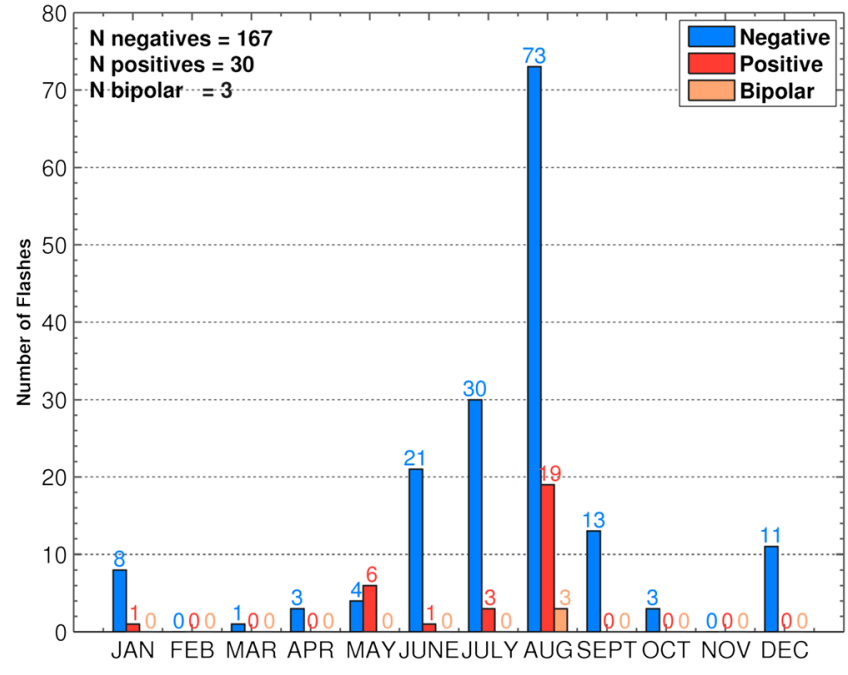

Figure 1. Monthly distribution of the number of flashes to the Säntis tower. June 2010 to January 2012.

[6] Negative and positive flashes observed on the Säntis tower (see Figure 1) are concentrated in the summer months, with August being the month during which most of the positive flashes occurred (6 events in 2010 and 16 events in 2011).

\section{Säntis Tower Experimental Setup}

[7] The Säntis tower is a $124 \mathrm{~m}$ tall tower sitting on the top of the $2502 \mathrm{~m}$ tall mount Säntis located at $47^{\circ} 14^{\prime} 57^{\prime \prime} \mathrm{N}$ and $9^{\circ}$ $20^{\prime} 32^{\prime \prime} \mathrm{E}$ in the Appenzell region in the northeast of Switzerland. The tower has a hollow, metallic inner conical structure of radius $2 \mathrm{~m}$ at the base and $1 \mathrm{~m}$ at its top. An outer Plexiglas structure has a radius of $3 \mathrm{~m}$ at the base and $1.5 \mathrm{~m}$ at the top. The structure serves mainly as a telecommunications tower and as a weather station. A decade-long analysis on the lightning incidence to several towers at various locations in Switzerland resulted in the choice of the Säntis tower, which is struck by lightning about 100 times a year, according to the European lightning detection network European Cooperation for Lightning Detection [Romero et al., 2012a].

[8] The Säntis tower has been instrumented using advanced and modern equipment including remote monitoring and control capabilities for accurate measurement of lightning current parameters [Romero et al., 2012b]. The lightning current is measured at two different heights, $24 \mathrm{~m}$ and $82 \mathrm{~m}$. At the lower height, we installed two Rogowski coils with different sensitivities, each one with an analog integrator to obtain the current waveform. One of these Rogowski sensors was manufactured by Power Electronic Measurements (PEM) Inc. and the other by ROCOIL. Two more sensors were installed at $82 \mathrm{~m}$. The first one is a PEM Rogowski coil with an analog integrator, while the second

Table 1. Current Peak, Total Transferred Charge, Flash Duration, Average Current, and Action Integral of Positive Flashes Recorded on the Säntis Tower ${ }^{\mathrm{a}}$

\begin{tabular}{|c|c|c|c|c|c|c|c|c|}
\hline Flash \# & Type & $\begin{array}{l}\text { Number and Time Tag } \\
\text { (dd.mm.yy hh.mm) }\end{array}$ & $\begin{array}{l}\text { Pulse Peak } \\
\text { (kA) }\end{array}$ & $\begin{array}{l}\text { Flash Peak } \\
(\mathrm{kA})\end{array}$ & $\begin{array}{c}\text { Flash Charge } \\
\text { Q (C) }\end{array}$ & $\begin{array}{c}\text { Flash Duration } \\
\Delta \mathrm{t}(\mathrm{ms})\end{array}$ & $\begin{array}{l}\text { Average Current } \\
\mathrm{Q} / \Delta \mathrm{t}(\mathrm{kA})\end{array}$ & $\begin{array}{l}\text { Action Integral } \\
\left(\times 10^{6} \mathrm{~A}^{2} \mathrm{~s}\right)\end{array}$ \\
\hline 1 & 1 & 21.07.2010 19:05 & 42.7 & - & 280.9 & 111 & 2.6 & 1.7 \\
\hline 2 & 1 & 21.07.2010 19:31 & 18.2 & - & 84 & 51 & 1.6 & 0.295 \\
\hline 3 & 2 & 01.08.2010 20:00 & 0.9 & 0.4 & 2.7 & 15 & 0.2 & 0.001 \\
\hline 4 & 2 & 01.08.2010 20:02 & 2.4 & 2.1 & 16.7 & 77 & 0.2 & 0.013 \\
\hline 5 & 2 & 01.08.2010 20:06 & 1 & 0.6 & 6.8 & 40 & 0.2 & 0.003 \\
\hline 6 & 2 & $15.08 .201014: 34$ & 13.2 & 9.1 & 189.1 & 55 & 3.4 & 0.798 \\
\hline 7 & 2 & $15.08 .201014: 37$ & 3.6 & 3.4 & 134.8 & 83 & 1.6 & 0.21 \\
\hline 8 & 2 & $30.08 .201004: 42$ & 6.5 & 4.9 & 153.4 & 68 & 2.3 & 0.366 \\
\hline 9 & 2 & $01.05 .201112: 36$ & 11.9 & 5.4 & 8.3 & 9 & 0.9 & 0.024 \\
\hline 10 & 2 & $20.05 .2011 \quad 15: 29$ & 21.7 & 9.6 & 30.2 & 12 & 2.5 & 0.219 \\
\hline 11 & 2 & $22.05 .201123: 48$ & 11.1 & 3.3 & 31.4 & 17 & 1.8 & 0.058 \\
\hline 12 & 2 & $26.05 .201117: 53$ & 2 & 1.6 & 19.5 & 60 & 0.3 & 0.013 \\
\hline 13 & 1 & $26.05 .201118: 00$ & 16.3 & - & 14.8 & 15 & 1 & 0.056 \\
\hline 14 & 1 & $26.05 .201118: 03$ & 31.5 & - & 41.1 & 40 & 1 & 0.135 \\
\hline 15 & 2 & $06.06 .201110: 36$ & 12.4 & 5.8 & 80.6 & 100 & 0.8 & 0.116 \\
\hline 16 & 2 & 08.07.2011 01:06 & 12 & 11.8 & 899.6 & 370 & 2.4 & 4.001 \\
\hline 17 & 1 & 03.08.2011 11:51 & 92.7 & - & 404.2 & 50 & 8 & 4.185 \\
\hline 18 & 2 & 03.08.2011 12:16 & 4.1 & 1.4 & 15 & 25 & 0.6 & 0.013 \\
\hline 19 & 2 & 27.08.2011 05:43 & 11.1 & 10.8 & 853.3 & 250 & 3.4 & 4.787 \\
\hline 20 & 2 & 27.08.2011 06:00 & 6.5 & 4.1 & 363.9 & 300 & 1.2 & 0.602 \\
\hline 21 & 2 & 27.08.2011 06:02 & 5.2 & 5.1 & 460 & 270 & 1.7 & 0.994 \\
\hline 22 & 2 & $27.08 .201106: 30$ & 25.9 & 25 & 913.3 & 260 & 3.5 & 7.193 \\
\hline 23 & 2 & $27.08 .201106: 37$ & 12.8 & 9.8 & 15 & 15 & 1 & 0.02 \\
\hline 24 & 2 & 27.08.2011 06:46 & 22.2 & 14.8 & 902 & 200 & 4.5 & 7.097 \\
\hline 25 & 2 & 27.08.2011 06:47 & 11 & 10.5 & 701.8 & 210 & 3.3 & 3.905 \\
\hline 26 & 2 & $27.08 .201106: 48$ & 10.4 & 8.8 & 537.7 & 240 & 2.2 & 2.342 \\
\hline 27 & 2 & 27.08.2011 06:50 & 12 & 8.8 & 700.9 & 250 & 2.8 & 3.319 \\
\hline 28 & 2 & 27.08.2011 08:38 & 9.3 & 8.8 & 184.7 & 170 & 1.1 & 0.662 \\
\hline 29 & 2 & 27.08.2011 08:47 & 8.1 & 3.5 & 225.7 & 165 & 1.4 & 0.424 \\
\hline \multirow[t]{4}{*}{30} & 2 & $05.01 .2012 \quad 17: 21$ & 9.2 & 8.2 & 512.5 & 165 & 3.1 & 2.799 \\
\hline & & Min: & 0.9 & 0.4 & 2.7 & 9 & 0.2 & 0.001 \\
\hline & & Median: & 11.1 & 5.8 & 169.1 & 80 & 1.7 & 0.395 \\
\hline & & Max: & 92.7 & 25 & 913.3 & 370 & 4.5 & 7.193 \\
\hline
\end{tabular}

${ }^{a}$ Pulse peak and flash peak currents are defined in Zhou et al. [2012] and illustated in Figure 8. 
ROMERO ET AL.: POSITIVE LIGHTNING SÄNTIS TOWER
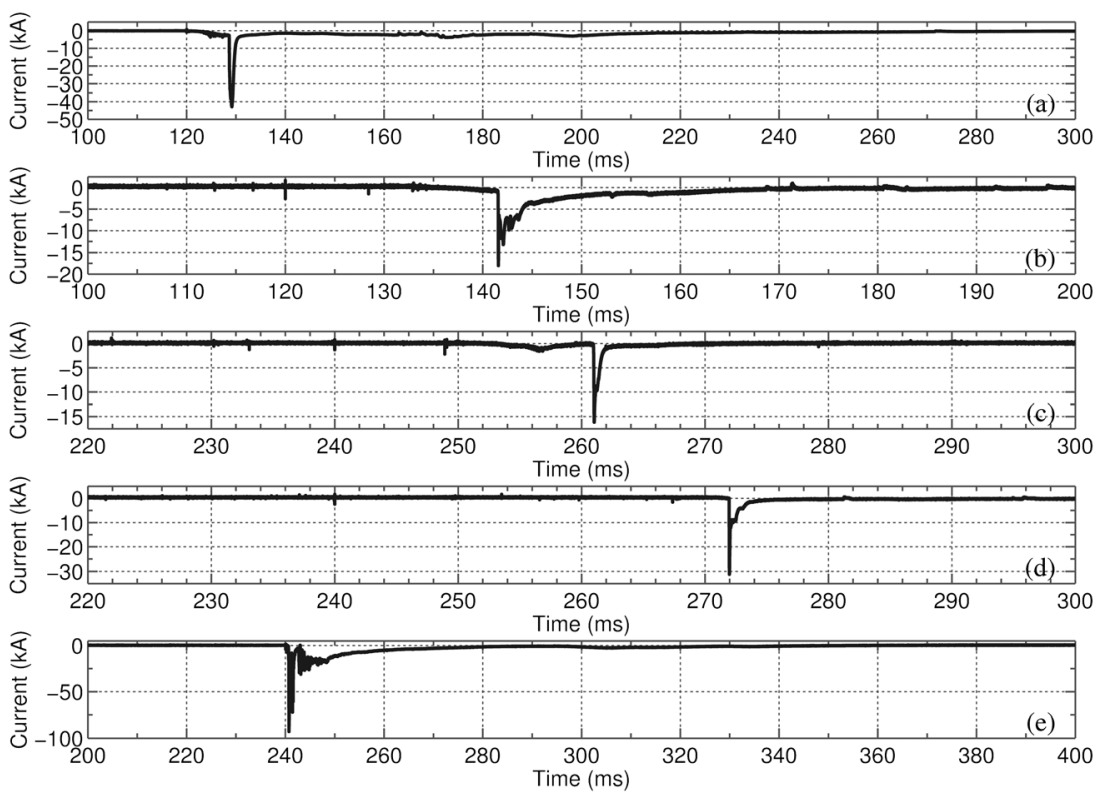

Figure 2. Measured current waveforms associated with type 1 positive flashes. (a) Flash \#1, (b) flash \#2, (c) flash \#13, (d) flash \#14, and (e) flash \#17. Flash IDs refer to Table 1. Note that waveforms are presented on different time scales.

one is a multigap magnetic loop (B-Dot) sensor specially designed to measure the lightning current derivative [Romero et al., 2012a]. The analog outputs of the sensors are

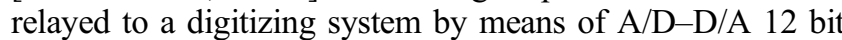
fiber optic links characterized by an overall bandwidth from DC to $25 \mathrm{MHz}$. The maximum current measurable with the PEM Rogowski coils is $120 \mathrm{kA}$, and the maximum current derivative measurable with the $\mathrm{B}-\mathrm{Dot}$ sensor is $400 \mathrm{kA} / \mu \mathrm{s}$. The PEM Rogowski coil located at $82 \mathrm{~m}$ is characterized by a frequency response ranging from $50 \mathrm{mHz}$ to $2.4 \mathrm{MHz}$, while the upper frequency limit of the B-Dot sensor is about $20 \mathrm{MHz}$ (for more details, see Romero et al. [2012a]). The measurement window for each flash is $1.2 \mathrm{~s}$ with a $0.25 \mathrm{~s}$ pretrigger and a sampling rate of $100 \mathrm{MHz}$. The current waveforms were obtained by combining the outputs of the PEM Rogowski coil and the multigap B-dot sensor (both located at $82 \mathrm{~m}$ ), using a procedure detailed in Romero et al. [2013]. The procedure effectively merges the low-

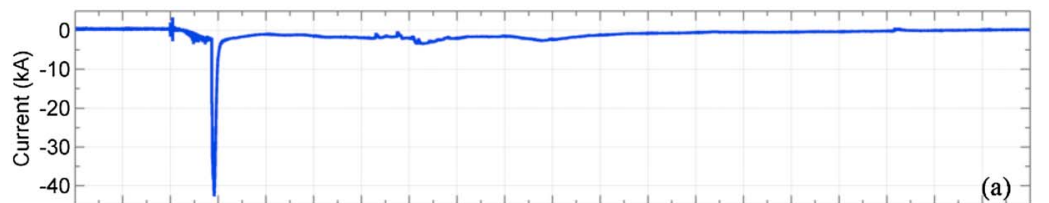

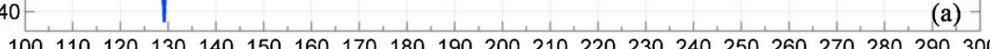
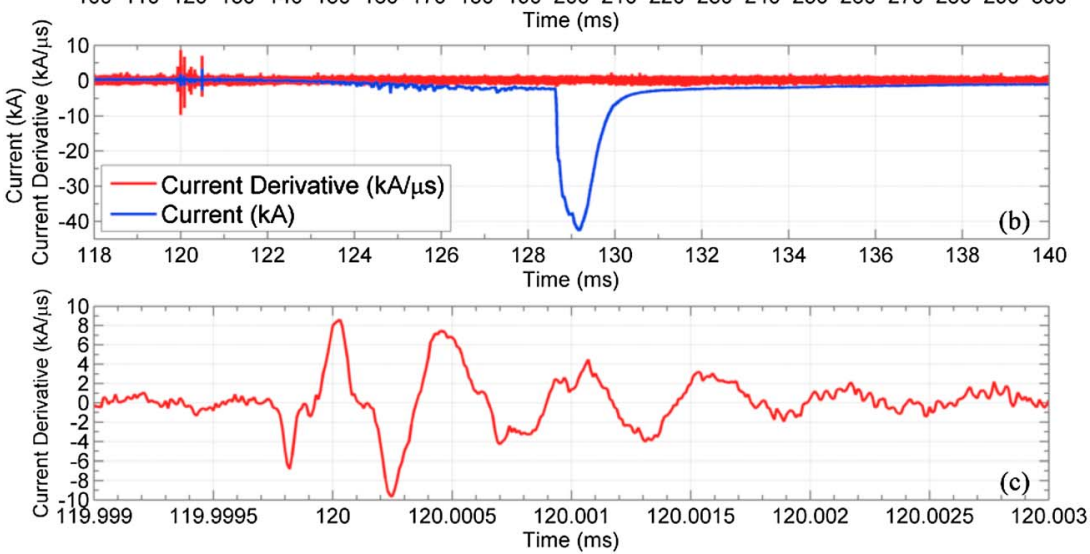

Figure 3. Type 1 current waveform associated with a positive flash recorded on 21 July 2010, 19:05 (flash\#1). (a) Current waveform for the entire flash displayed on a $200 \mathrm{~ms}$ time scale. (b) Expanded view of the initial portion of the current (blue) and current derivative (red) records displayed on a $22 \mathrm{~ms}$ time scale. (c) Expanded view of the fastest pulse occurring at about $120 \mathrm{~ms}$, displayed on a $4 \mu$ s time scale. 
ROMERO ET AL.: POSITIVE LIGHTNING SÄNTIS TOWER
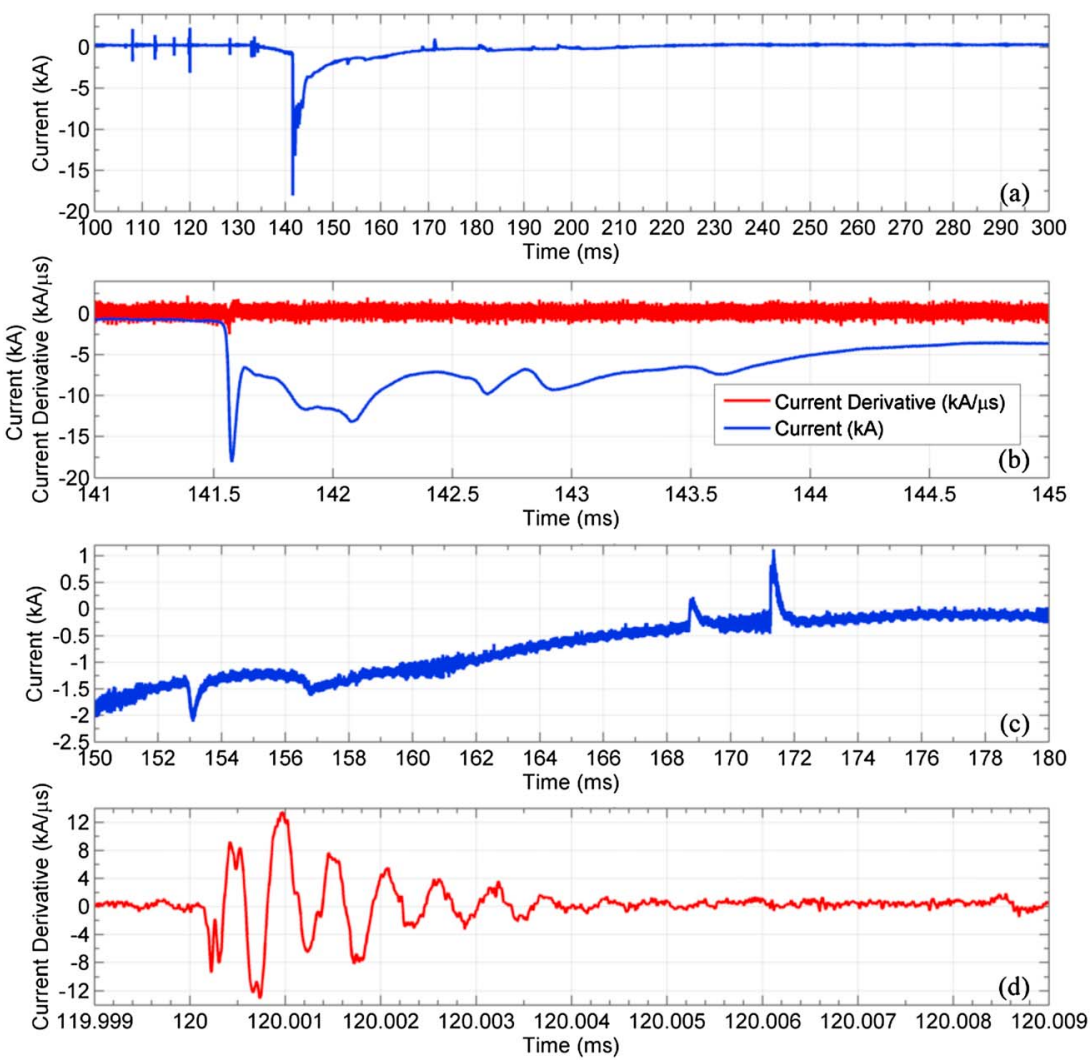

Figure 4. (a) Type 1 overall current waveform associated with a positive flash recorded on 21 July 2010,19:31 (flash \#2). (b) Expanded view of the main pulse. (c) Expanded view of the current waveform showing zero crossings due to two positive-polarity pulses at about 169 and $171 \mathrm{~ms}$. (d) Expanded view of current derivative of the fastest oscillatory pulse occurring at about $120 \mathrm{~ms}$.
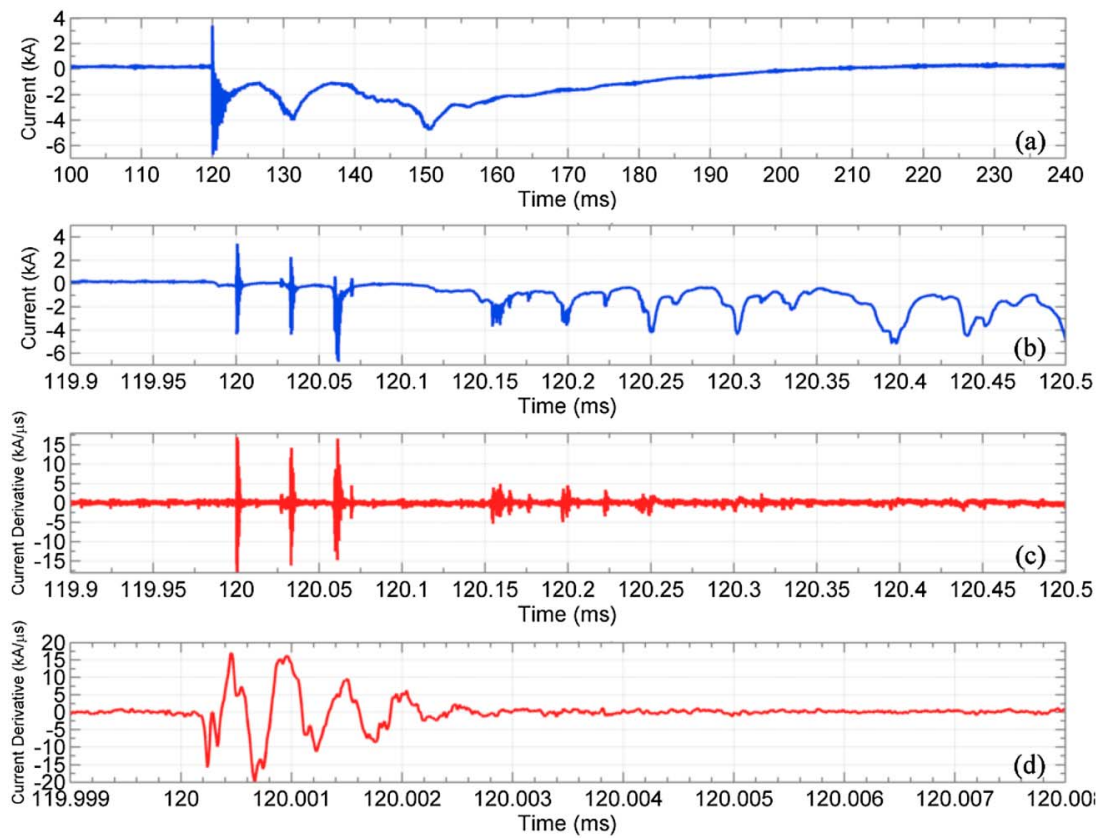

Figure 5. Type 2 current waveform associated with a positive flash recorded on 30 August 2010 at 04:42 (flash \#8). (a) Overall flash record (140 ms full scale), (b) initial part of the current record between 119.9 and $120.5 \mathrm{~ms}$, (c) current derivative record between 119.9 and $120.5 \mathrm{~ms}$ (600 $\mu$ s full scale), and (d) expanded view of the time derivative of the fastest pulse (occurring at about $120 \mathrm{~ms}$ ). 

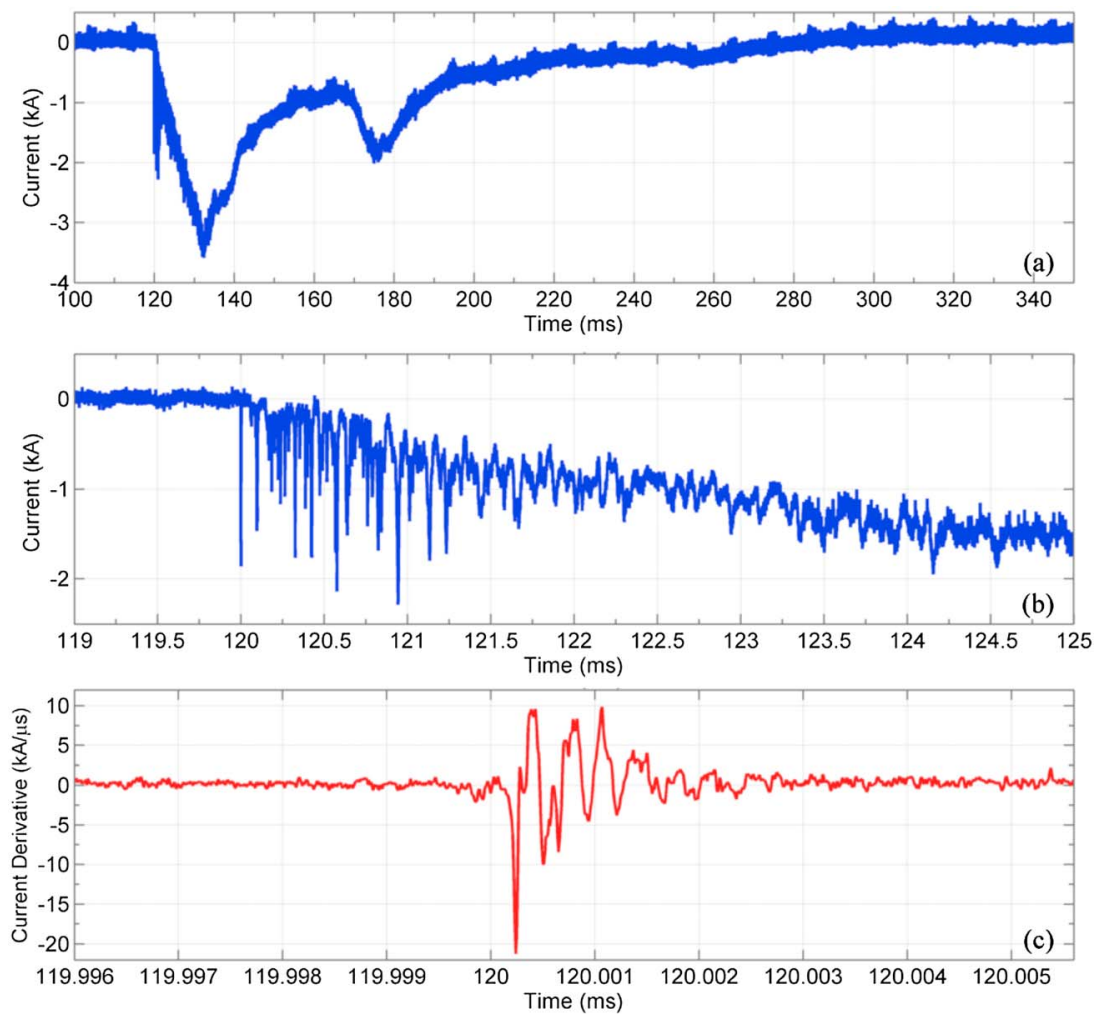

Figure 6. Type 2 current waveform of a positive flash recorded on 15 August 2010 at 14:37 (flash\#7). (a) Overall current record ( $250 \mathrm{~ms}$ full scale). (b) Expanded view of the initial rising portion (6 ms full time scale). (c) Expanded view of the current derivative of the first fast pulse (9 $\mu$ s full time scale).

frequency contents from the PEM Rogowski coil and the highfrequency contents of the multigap B-dot sensor (beyond $1 \mathrm{MHz}$ or so) to obtain a current waveform covering a wider frequency band than does either of the individual sensors (see also Romero et al. [2012b]).

[9] The status and settings of each pair of sensors can be monitored and changed by means of a control system designed and built using National Instruments CompactRIO modules linked via fiber optic links using 100Base-FX Ethernet. A local server running, monitoring, and storage tasks is housed in a shielded control room several tens of meters from the base of the tower. The server and the front end station are connected to the Internet over a router and a standard digital subscriber line link, allowing remote
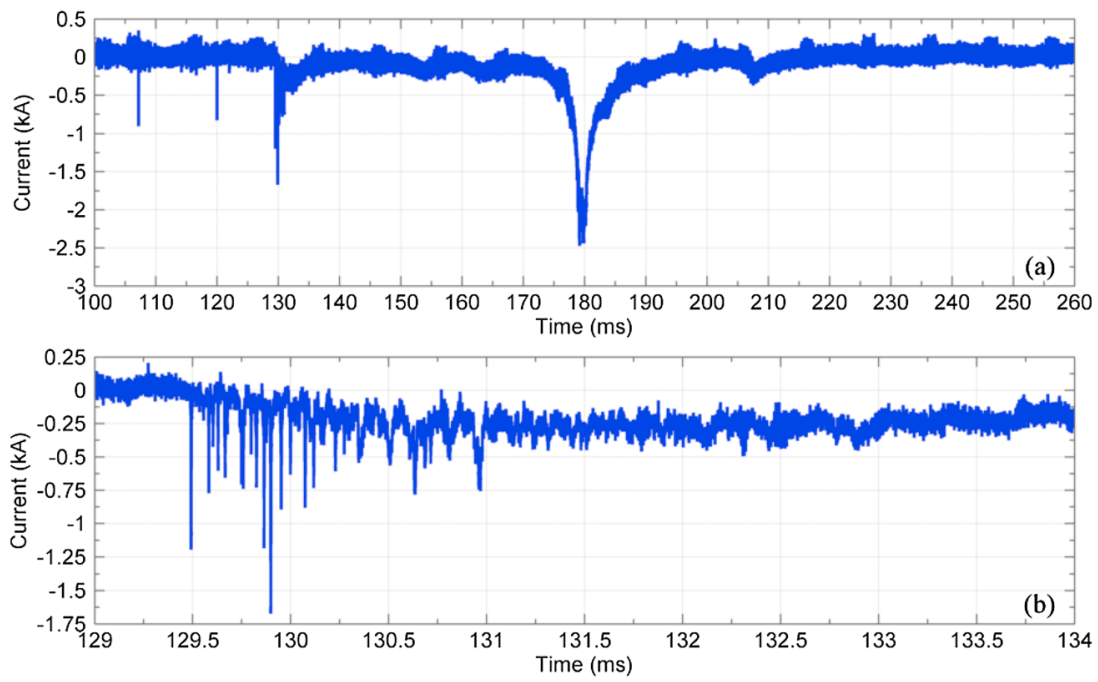

Figure 7. Type 2 current waveform of a positive flash recorded on 1 August 2010 at 20:02 (flash\#4). (a) Overall flash current record (160 ms full scale). (b) Portion of the current record between 129 and $134 \mathrm{~ms}$ (5 ms full scale). 

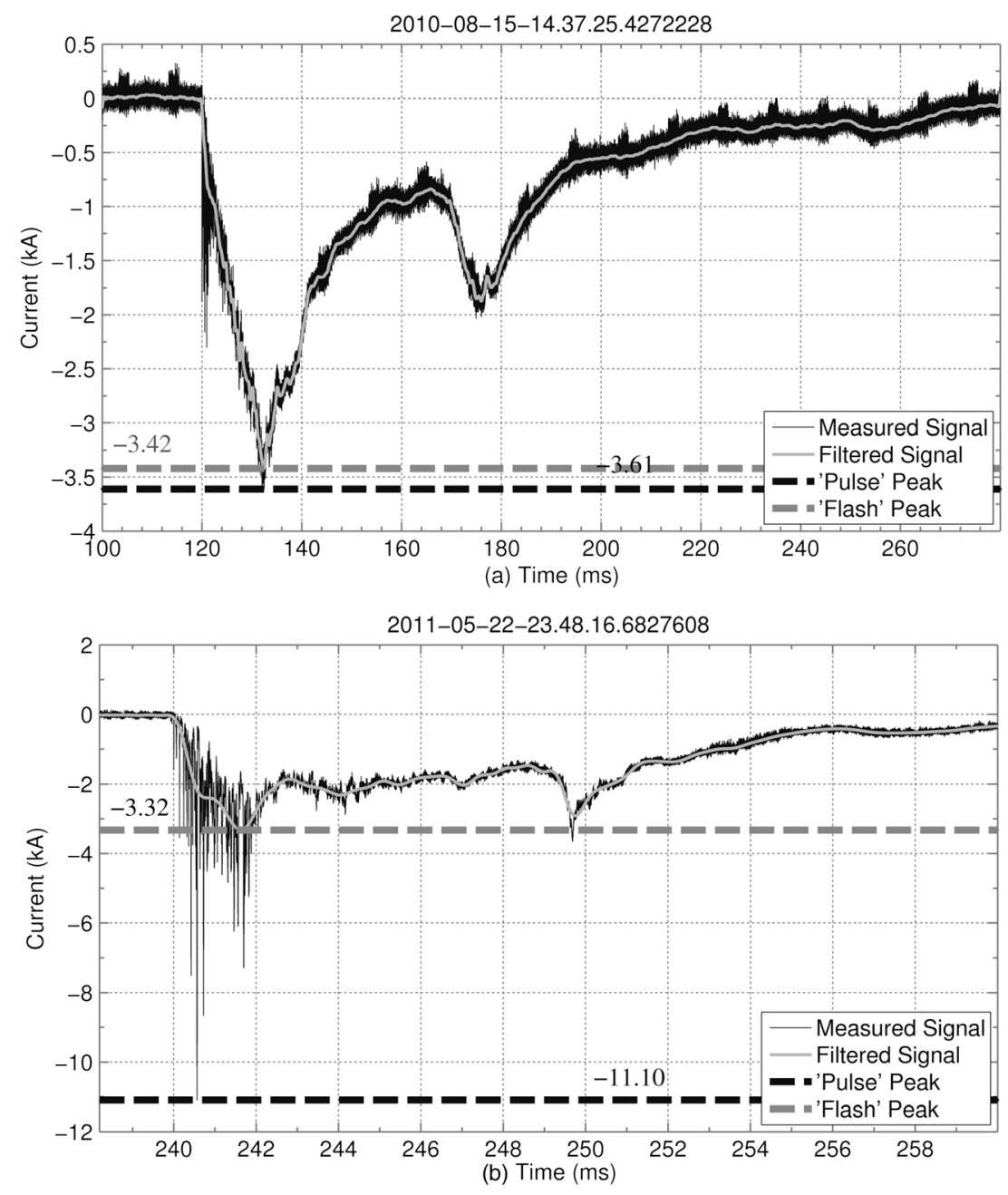

Figure 8. llustration of the pulse peak current and flash peak current for two measured waveforms of type 2. (a) Flash \#7, 15 August 2010 at 14.37. (b) Flash\#11, 22 May 2011 at 23:48. Both current peaks are measured with respect to zero level.

maintenance, monitoring, and control of the overall measurement system. More details on the measurement system installed on the Säntis tower can be found in Romero et al. [2012a, 2012b].

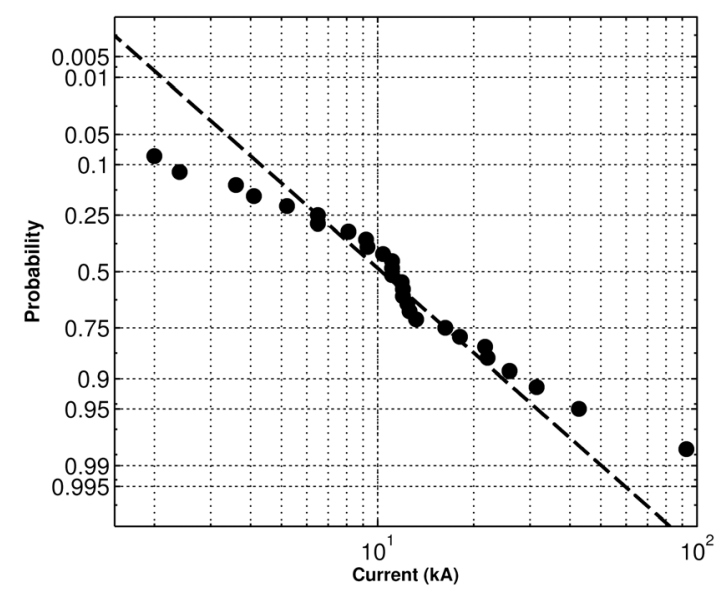

Figure 9. Pulse peak current cumulative frequency distribution.

\section{Data}

[10] Table 1 presents values of the current pulse and flash peaks, total transferred charge, flash duration, and action integral for the recorded positive flashes. Pulse peak and flash peak currents are defined in Zhou et al. [2012] (they will be discussed in section 4.1).

[11] The observed current waveforms were classified into two types, as described in the following section. Note that, throughout this paper, negative current polarity indicates positive charge transfer to ground. All flashes examined in this paper appeared to be of upward type, although all five type 1 flashes could be viewed as downward flashes with very long upward connecting leaders.

\subsection{Classification of Current Waveforms Associated With Positive Flashes}

\subsection{Type 1}

[12] Five of the 30 recorded positive flashes were characterized by the presence of a large unipolar current pulse with characteristics similar to those measured by Berger and coworkers [Berger, 1977, Figure 18; Berger et al., 1975, 


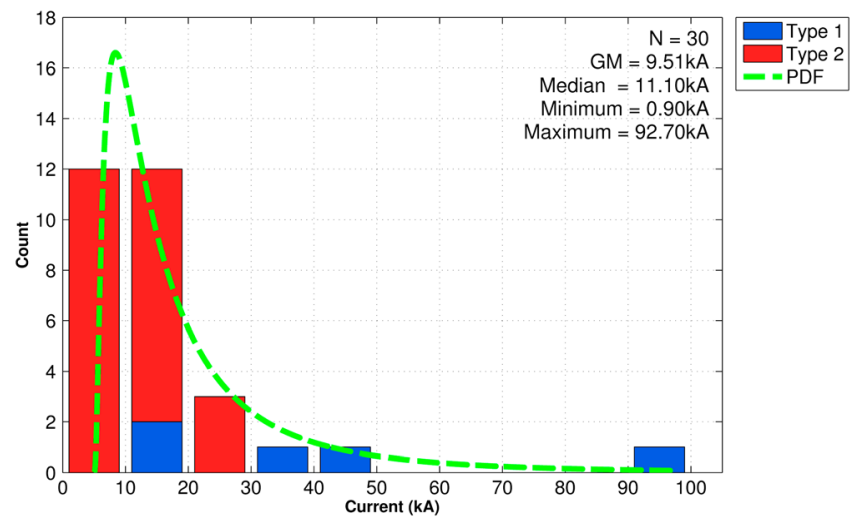

Figure 10. Pulse peak current histogram. The MLE (maximum-likelihood estimation) of the probability distribution function (PDF, broken green line) is also shown. $\mathrm{N}$ is the sample size and GM is the geometrical mean.

Figure 11]. Figure 2 presents current waveforms associated with all these five flashes. The risetime of the pulses was a few tens of microseconds for four of the five cases and about $380 \mu$ s for the fifth flash (flash \#1). In four of the five cases, namely, flashes \#2,13,14, and 17, the main pulse exhibited structure after the main peak in the form of subsidiary peaks separated by times of the order of $1 \mathrm{~ms}$. As can be seen from Figure 2, in three flashes $(\# 1,2,13)$, the main pulse was preceded by a clearly discernible initial slowly rising ramp lasting a few milliseconds [Romero et al., 2011], and it was followed by a steady current that contained pulses of both polarities (not well resolved in Figure 2), whose shapes are characteristic of $M$ components. Several milliseconds to several tens of milliseconds prior to the start of the initial slowly rising ramp, a train of damped oscillatory pulses separated by several milliseconds and characterized by the highest current steepnesses of the flash can be observed in three of the flashes $(\# 2,13,14)$. Note also that flash 1 exhibits a single burst of pulses (at about $120 \mathrm{~ms}$ ), with characteristics similar to those observed in flashes 2,13, and 14. Note that the peak current derivative associated with the main pulse occurring at about $128.6 \mathrm{~ms}$ is below the noise level (which in this case is about $2 \mathrm{kA} / \mu \mathrm{s})$.

[13] In Figure 3a, we show the overall waveform for a type 1 flash recorded on 21 July 2010 at 19:05 (flash \#1), also seen in Figure 2a. Figure 3b shows initial portions of current and current derivative records on an expanded time scale. The peak value of the main pulse is $42.7 \mathrm{kA}$, its $10-90 \%$ risetime is about $380 \mu \mathrm{s}$, and the total charge transferred to ground is $281 \mathrm{C}$. It can be seen that the highest pulse steepness (maximum current derivative) occurs about $3 \mathrm{~ms}$ prior to the initial slowly rising portion of the current. This activity prior to the main pulse might be associated with the streamer corona at the onset of the upward negative leader, or it may be induced in the tower by cloud discharges.

[14] Figure 3c shows, on a $4 \mu$ s time scale, the fastest of these current pulses (which occurred at a time of about $120 \mathrm{~ms}$ ), where the time derivative of the current measured by the B-dot sensor is also shown. It can be seen that the current and the current derivative exhibit an oscillatory behavior with a frequency of about $2.3 \mathrm{MHz}$, which corresponds to a wavelength of about $130 \mathrm{~m}$ at the speed of light.

[15] Figure 4a presents another type 1 positive flash corresponding to Figure $2 b$, recorded on the same day (21 July) at 19:31. The initial, slowly rising portion lasts about $10 \mathrm{~ms}$, at the end of which the current has reached a value of $1 \mathrm{kA}$. The peak value of the main pulse is $18.2 \mathrm{kA}$, its $10-90 \%$ risetime is about $20 \mu \mathrm{s}$, and the total charge transferred to ground is 84 C. An expanded view of the main current pulse along with the corresponding current derivative record is shown, on a $4 \mathrm{~ms}$ time scale, in Figure $4 \mathrm{~b}$, in which the relatively slow subsidiary peaks are visible after the initial peak.

[16] Positive and negative (relative to the steady background current) $M$ component-like pulses are seen during the steady current (between 150 and $180 \mathrm{~ms}$ ), in Figure 4c. It is worth noting that flash \#2 can be viewed as bipolar, with

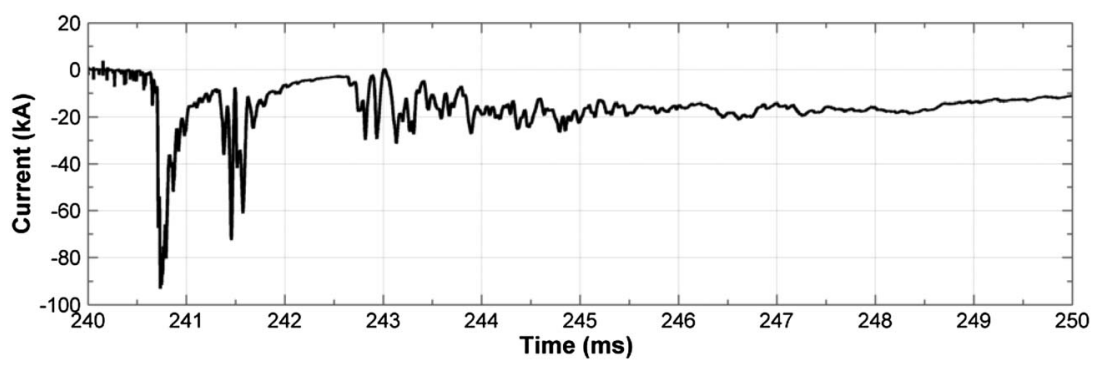

Figure 11. Current waveform associated with a type 1 positive flash that occurred on 3 August 2011 at 11:51 (flash \#17), displayed on a $10 \mathrm{~ms}$ time scale. The pulse peak of this waveform is $93 \mathrm{kA}$, the largest in our data set. 


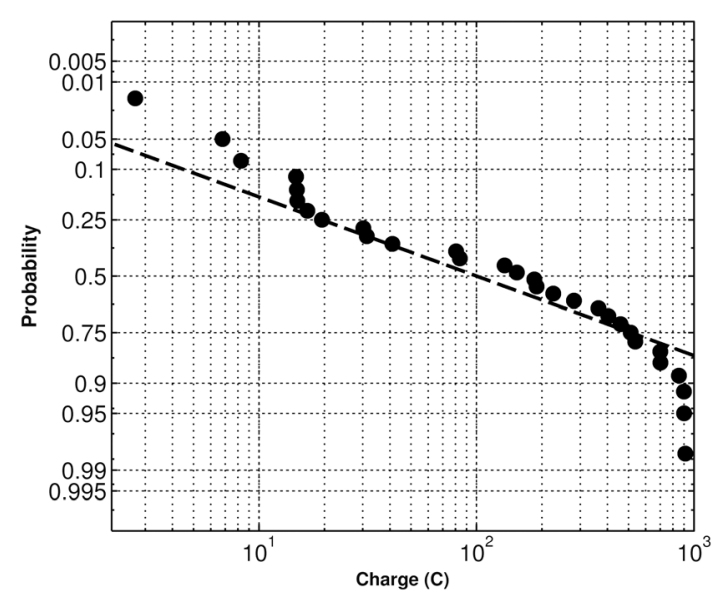

Figure 12. Cumulative frequency distribution of transferred charge $(\mathrm{N}=30)$.

polarity reversals due to $M$ component-like pulses occurring between 168 and $172 \mathrm{~ms}$. The occurrence of $M$ components in positive flashes was recently reported by Campos et al. [2009] who analyzed the luminosity-versus-time profiles obtained using a high-speed video camera. Our data appear to confirm the findings of Campos and coworkers and, to the best of our knowledge, constitute the first direct evidence of $M$ component-like current pulses of both polarities in positive flashes. Note that some $M$ component-like current waveforms of only one polarity can be seen in the data presented by Goto and Narita [1995] (see their Figure 10).

[17] Bursts of fast pulses can be seen in Figure 4a at about $107 \mathrm{~ms}, 112 \mathrm{~ms}, 117 \mathrm{~ms}, 120 \mathrm{~ms}$, and immediately prior to the initial slow rise of the main pulse. Figure $4 d$ shows an expanded view (10 $\mu$ s time scale) of the time derivative of the largest fast current pulse that occurred at about $120 \mathrm{~ms}$. The pulse exhibits oscillations (in this case with a frequency of about $1.7 \mathrm{MHz}$ ) that could be associated with the onset of the upward negative leader or induced in the tower by cloud discharges. In the former case, these oscillations can be viewed as being due to attempted negative leader processes similar to those observed to occur prior to the formation of a sustained upward positive leader in rocket-triggered lightning (see, for example, [Rakov and Uman, 2003, Figure 7.9 and 7.10]). If so, our data constitute the first documented evidence of attempted negative leader process in upward positive lightning.

\subsection{Type 2}

[18] The second type of observed positive flashes is characterized by a relatively slow (millisecond scale) waveform (see an example shown in Figure 5a) with large, oscillatory pulse trains superimposed on the initial rising portion of the waveform. The initial slow pulse is followed by one or more smaller slow pulses superimposed on a steady current and exhibiting rise and fall times of the order of $10 \mathrm{~ms}$ or more (examples are the pulses peaking at around $130 \mathrm{~ms}$ and $150 \mathrm{~ms}$ in Figure 5a). The pulses superimposed on the rising part of the initial slow waveform have risetimes of the order of microseconds and are separated by time intervals of some tens of microseconds; they are inferred to be due to an upward negative stepped leader [Wada et al., 1996; Rakov, 2003; Diendorfer et al., 2006; Zhou et al., 2012]. The overall peak current of type 2 flashes is typically associated with one of these fast pulses.

[19] Figure 5a presents the overall current waveform associated with a positive flash of the second type recorded on 30 August 2010 with a current peak of $6.5 \mathrm{kA}$. Figure $5 \mathrm{~b}$ presents an expanded view of the fast pulses superimposed on the rising portion of the initial slow waveform. These successive pulses are separated by time intervals of about $50 \mu \mathrm{s}$. In Figure 5c, we have plotted, on a $600 \mu \mathrm{s}$ time scale, the time derivative of the current measured using the B-dot sensor. It can be seen that the highest steepnesses (in excess of $15 \mathrm{kA} / \mu \mathrm{s}$ ) are associated with the initial pulses.

[20] Figure $5 \mathrm{~d}$ presents the time derivative of one of the fast current pulses that occurred at about $120 \mathrm{~ms}$. The pulse exhibits a damped oscillatory behavior, with a frequency of oscillations of about $1.9 \mathrm{MHz}$, very similar to the frequency of oscillation of the bursts of fast pulses observed in type 1 flashes. These oscillatory pulses are presumably due to the onset of upward negative stepped leader.

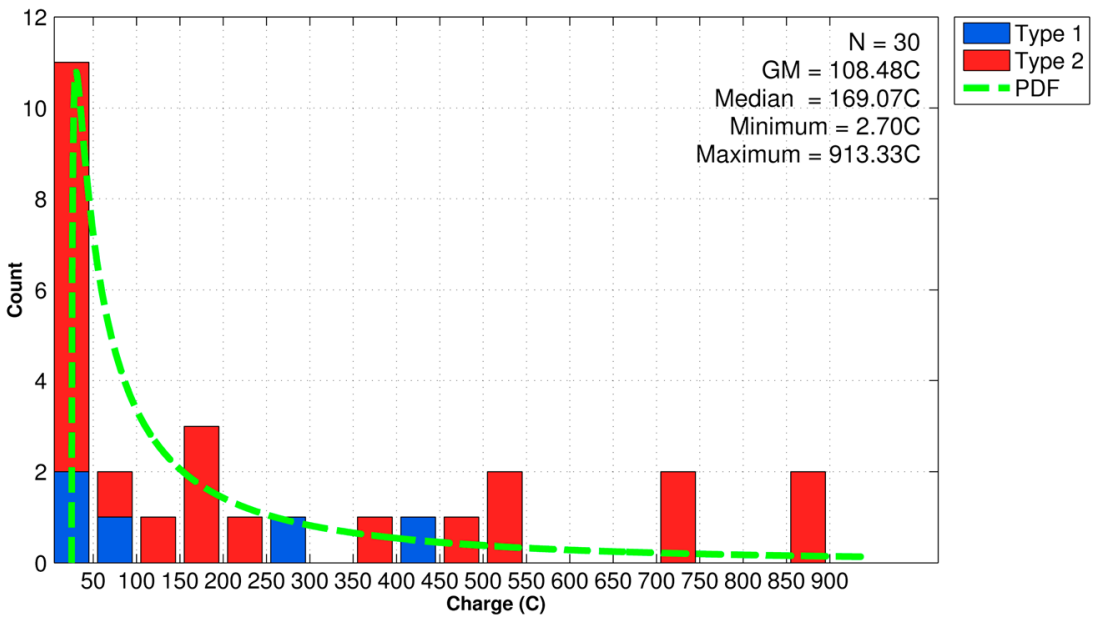

Figure 13. Charge histogram. The MLE (maximum-likelihood estimation) PDF (broken green line) is also shown. 


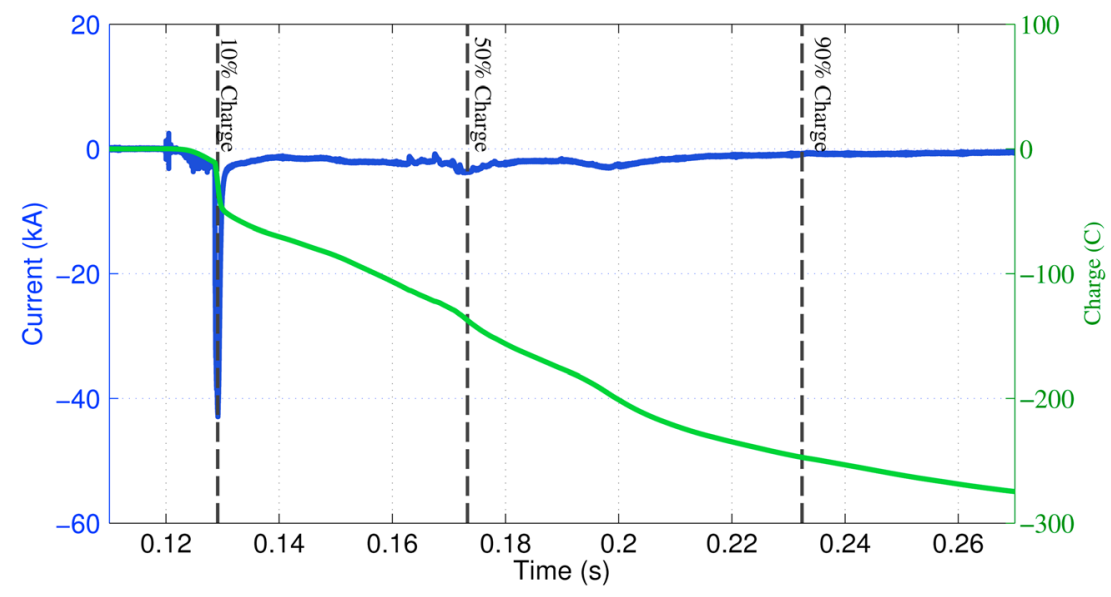

Figure 14. Flash \#1 that occurred on 21 July 2010, 19:05. This flash was classified as type 1 and transferred to ground $281 \mathrm{C}$ of positive charge. Current (left scale) is shown in blue and charge (right scale) in green.

[21] Another example of overall current waveform associated with the second type is shown in Figure 6a. Again, this current is characterized by an initial phase with fast pulses superimposed on the rising part of the first slow pulse. The slow portion of the waveform in this flash has a relatively low peak value of $3.4 \mathrm{kA}$ and a risetime of $12 \mathrm{~ms}$. Figure $6 \mathrm{~b}$ shows an expanded view of the initial rising part of the first slow pulse, in which the multiple fast pulses are clearly discernible. The time derivative of the first fast pulse is shown on an expanded time scale in Figure 6c.

[22] Figure 7 shows the current associated with another positive flash classified as type 2, recorded on 1 August 2010 (flash \#4). The main slow pulse in this waveform is preceded by bursts of fast pulses that can be seen at about $107 \mathrm{~ms}, 118 \mathrm{~ms}$, and $120 \mathrm{~ms}$. At about $129 \mathrm{~ms}$, the current exhibits a relatively slow waveform with oscillatory pulse trains superimposed on its initial rising portion (see Figure $7 \mathrm{~b}$ ). In this case, a second slow waveform, peaking at about $180 \mathrm{~ms}$ and lasting about $15 \mathrm{~ms}$, appears after about $40 \mathrm{~ms}$ interval. Figure $7 \mathrm{~b}$ shows details of the waveform in the time window of $129 \mathrm{~ms}$ to $134 \mathrm{~ms}$, where fast repetitive pulses are clearly noticeable in the rising portion of the first relatively slow pulse. Note that no fast pulses are seen in the second slow waveform. Also note that this behavior (absence of fast pulses) is very similar to that of subsidiary slow pulses in the flashes shown in Figure 5 (peaking at $132 \mathrm{~ms}$ and $150 \mathrm{~ms}$ ) and Figure 6 (peaking at $175 \mathrm{~ms}$ ).

\section{Statistical Analysis of Positive Flashes}

[23] Table 1 summarizes the values of peak current, charge, duration, and action integral associated with the recorded positive flash current waveforms. In this section, we present the statistics associated with the salient parameters (derivable from current records) of these positive flashes, with reference to available data obtained at other instrumented towers.

\subsection{Peak Current}

[24] Zhou et al. [2012] defined two parameters associated with the current peak : (1) the "pulse peak current" which is the difference between the maximum current value of the

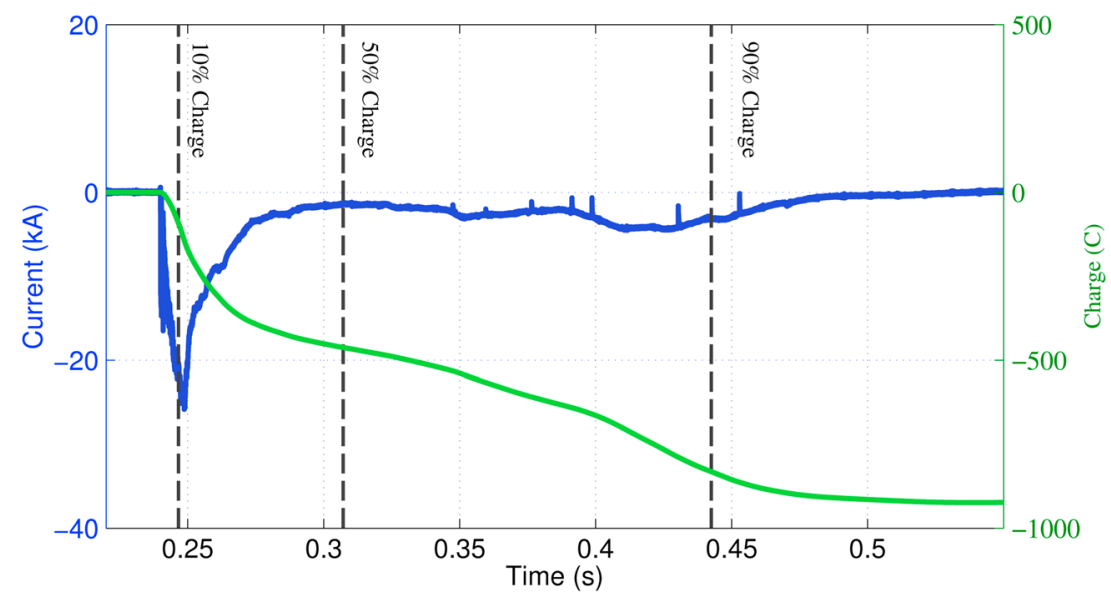

Figure 15. Flash \#22 that occurred on 27 August 2011, 6:30. This flash was classified as type 2 and transferred to ground $913 \mathrm{C}$ of positive charge. Current (left scale) is shown in blue and charge (right scale) in green. 


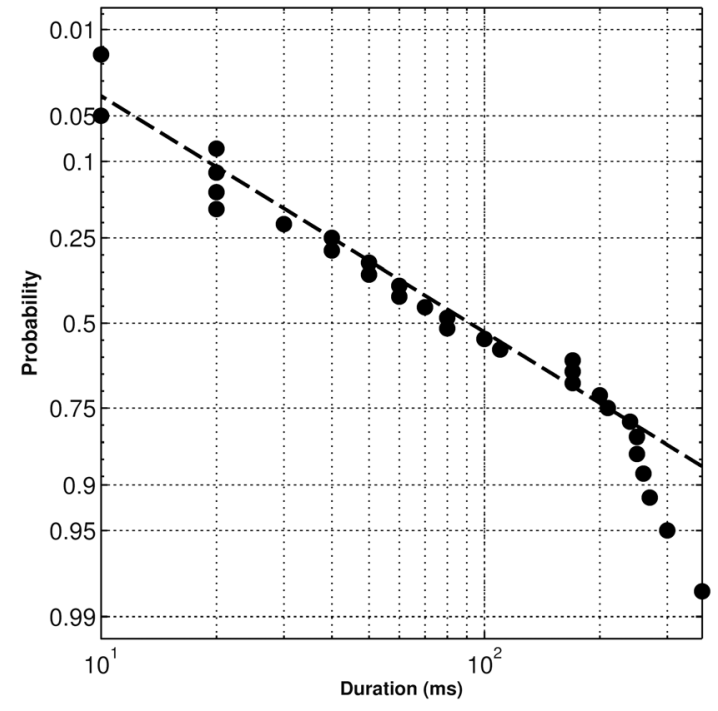

Figure 16. Cumulative frequency distribution of flash duration $(\mathrm{N}=30)$.

flash and the no-current (zero) level and (2) the "flash peak current" which is the maximum of the underlying slowly varying current and the no-current (zero) level. These two definitions are illustrated in Figure 8 for two different flashes of type 2. The underlying slow waveform, used for measuring the flash peak current, was obtained by applying a $1 \mathrm{kHz}$ low-pass filter to the waveforms. Note that the distinction between pulse and flash peaks is only needed for flashes of type 2 (only pulse peaks are given for type 1 flashes in Table 1).

[25] Figure 9 presents the cumulative frequency distribution of pulse peak currents for all 30 events combined, and Figure 10 presents the corresponding histogram. Although the overall shape of the histogram is indicative of a lognormal distribution, some deviations are observed both for very low and for very high values. These could be due in part to the small sample size. Note that the highest peak currents are associated with type 1 flashes.
[26] The maximum measured value of the peak current during the entire period of observation is $92.7 \mathrm{kA}$ (see Figure 11). It was measured in flash \#17 that occurred on 3 August 2011 at 11:51. This flash was classified as type 1 . Note that in this case the main pulse had considerable fine structure and was followed within a few milliseconds by more structure in the form of relatively fast pulses superimposed on steady current. Many of these pulses have peaks of the order of tens of kiloampere, up to a maximum of $72 \mathrm{kA}$. The median for the pulse peak current is found to be $11.1 \mathrm{kA}$ (31.5 kA for type 1 and $10.4 \mathrm{kA}$ for type 2$)$.

\subsection{Total Transferred Charge}

[27] Figures 12 and 13 show respectively the cumulative probability plot and the histogram of the transferred charge. As with the peak current, the histogram and the cumulative probability plots exhibit the overall characteristics of a lognormal distribution with some deviation for the very high and the very low values which can be attributed, at least in part, to the small sample size. The median is found to be $169 \mathrm{C}$ (84 C for type 1 and $185 \mathrm{C}$ for type 2 ).

[28] An example of a flash transferring a large amount of charge is presented in Figure 14. This is a type 1 flash that transferred $280 \mathrm{C}$ of charge to ground. In this figure, vertical lines show the times corresponding to $10 \%, 50 \%$, and $90 \%$ of the total transferred charge.

[29] It is worth observing that 8 flashes (all of type 2) out of 30 transported to ground positive charge in excess of $500 \mathrm{C}$ (see Table 1). The largest amount of transferred charge in our data set corresponds to flash \#22 that occurred on 27 August 2011 and is shown in Figure 15. The amount of charge transferred during this flash $(913 \mathrm{C})$ is close to the highest charge transfer of about $1000 \mathrm{C}$ ever measured for positive and negative winter lightning in Japan [Miyake et al., 1992].

\subsection{Flash Duration}

[30] Figures 16 and 17 present the cumulative probability plot and the histogram for the flash duration. The median duration is found to be $80 \mathrm{~ms}(50 \mathrm{~ms}$ for type 1 and $100 \mathrm{~ms}$

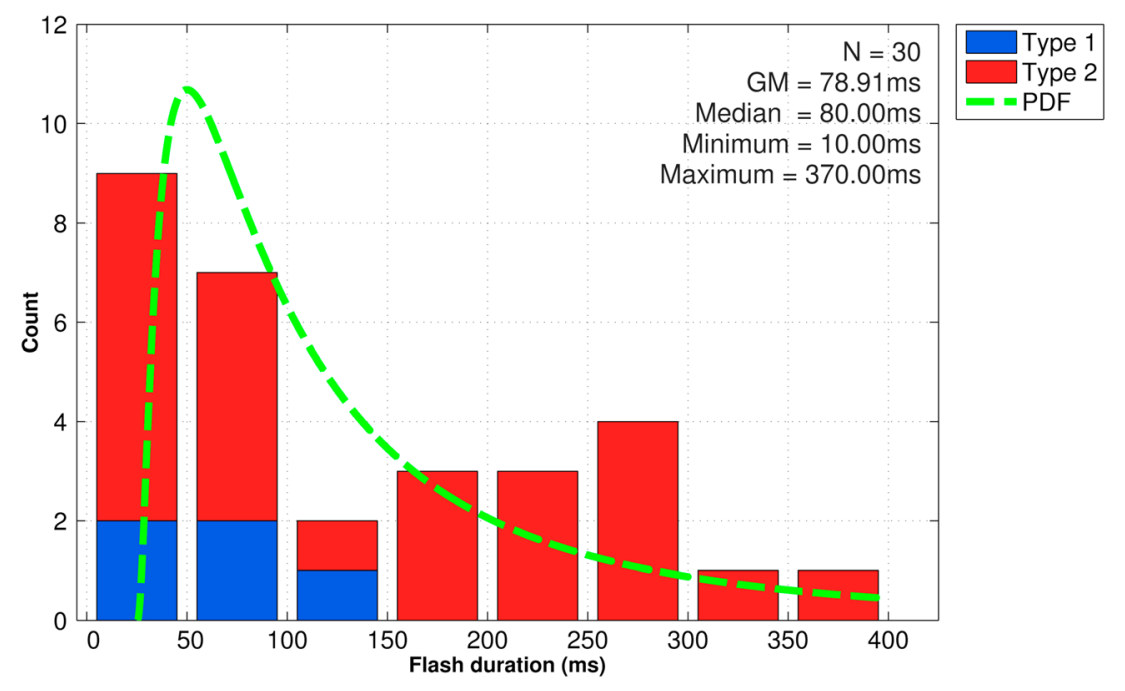

Figure 17. Flash duration histogram. The MLE (maximum-likelihood estimation) PDF (broken green line) is also shown. 


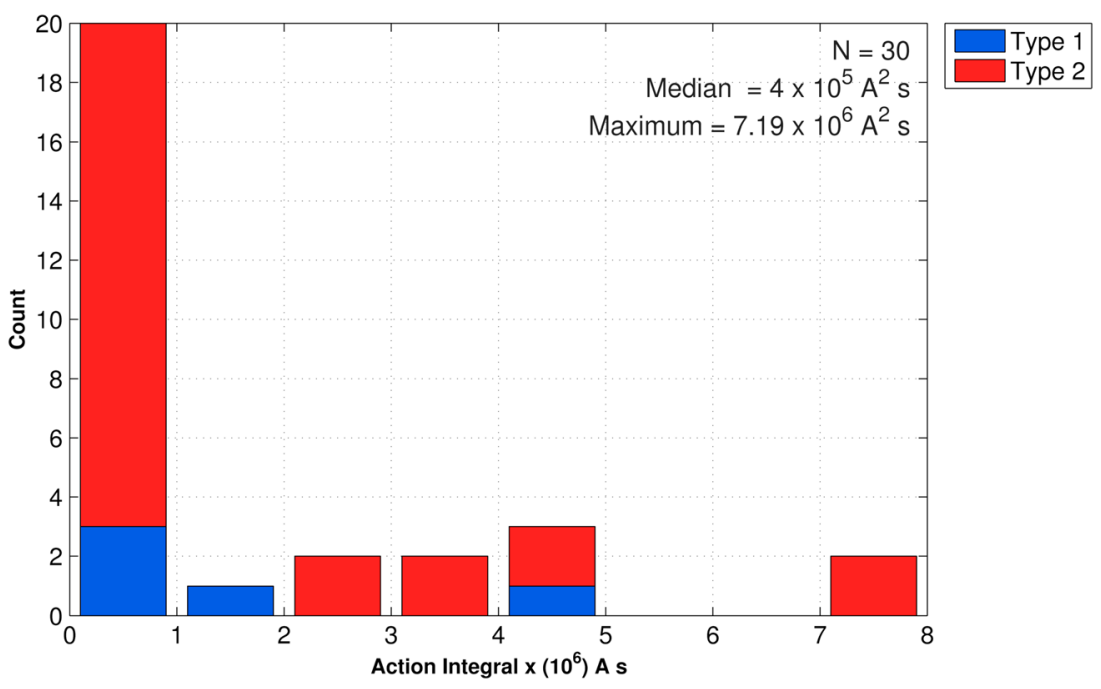

Figure 18. Action integral histogram.

for type 2). Note that type 1 flashes tend to have shorter durations than type 2 flashes.

\subsection{Action Integral}

[31] The histogram of action integral is presented in Figure 18. The measured values are characterized by a median of $4 \cdot 10^{5} \mathrm{~A}^{2} \mathrm{~s}\left(3 \cdot 10^{5} \mathrm{~A}^{2} \mathrm{~s}\right.$ for type 1 and $4.2 \cdot 10^{5}$
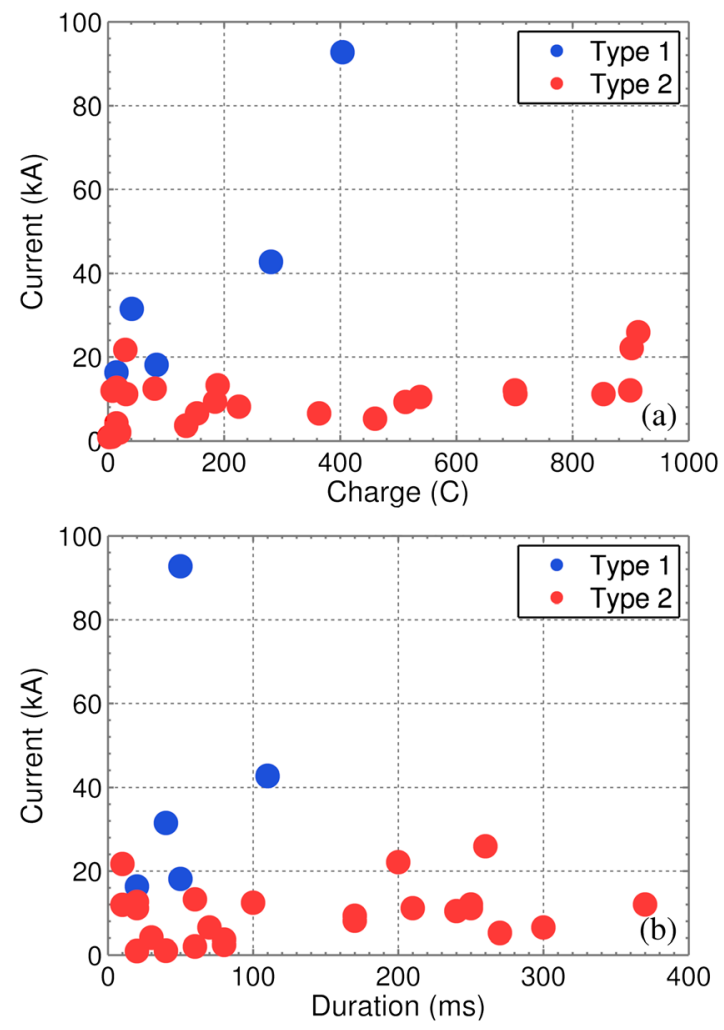

Figure 19. (a) Pulse peak current versus transferred charge. (b) Pulse peak current versus flash duration.
$\mathrm{A}^{2} \mathrm{~s}$ for type 2) and a maximum value of $7.19 \cdot 10^{6} \mathrm{~A}^{2} \mathrm{~s}$. These values are significantly larger than those reported for 10 years of observations at the Gaisberg tower [Zhou et al., $2012]$, with a median of $1.6 \cdot 10^{5} \mathrm{~A}^{2} \mathrm{~s}$ and a maximum of $2 \cdot 10^{6} \mathrm{~A}^{2} \mathrm{~s}$. Two thirds of the observed values remain, nevertheless, below $10^{6} \mathrm{~A}^{2} \mathrm{~s}$.

\subsection{Correlation Between Parameters}

[32] Figures 19a and 19b present the pulse peak current as a function of the charge and flash duration, respectively. It can be seen that the correlation between the peak current and the charge/duration is very different for type 1 and type 2 flashes. While the peak currents for type 2 flashes remain below about $25 \mathrm{kA}$ regardless of the transferred charge, the peak current in type 1 flashes tends to increase with increasing transferred charge or duration. It should be noted, however, that the number of type 1 flashes is quite small to draw definitive conclusions.

\section{Discussion}

[33] Table 2 presents a summary of median values of the pulse peak current, transferred charge, and flash duration for all 30 upward positive events examined in this study and their counterparts from other studies in Switzerland (Monte San Salvatore) [Berger, 1977], Japan [Miki et al., 2010], and Austria (Gaisberg tower) [Zhou et al., 2012]. The sample size is given in the parentheses.

[34] It can be seen that our median values for the peak current and the flash duration are similar to those based on the data obtained recently in Austria.

[35] The amount of transferred charge is substantially larger in our data set, with a median of $169 \mathrm{C}$, than in other studies. This value is about 6 times as large as those obtained at Monte San Salvatore [Berger, 1977] and in Japan [Miki et al., 2010] and about 3 times larger than the value obtained in Austria [Zhou et al., 2012].

[36] The values for the average current calculated as the ratio of the charge transfer and the flash duration range from 200 A to $4.5 \mathrm{kA}$ (see Table 1). The median value, $1.7 \mathrm{kA}$, is 
Table 2. Comparison of Median Values of Upward Positive Lightning Parameters From Different Studies ${ }^{\mathrm{a}}$

\begin{tabular}{lcccr}
\hline Study & Peak Current $(\mathrm{kA})$ & Flash Duration $(\mathrm{ms})$ & Charge Transfer $(\mathrm{C})$ & Action Integral $\left(\times 10^{6} \mathrm{~A}^{2} \mathrm{~s}\right)$ \\
\hline Monte San Salvatore, Switzerland [Berger, 1977] & $1.5(132)$ & $72(138)$ & $26(137)$ & - \\
Nikaho Kougen Wind Farm, Japan [Miki et al., 2010] & $6.5(16)$ & $40(16)$ & $30.2(16)$ & - \\
Gaisberg Tower, Austria [Zhou et al., 2012] & $11^{\mathrm{b}}(26)$ & $82(26)$ & $58(26)$ & $0.16(25)$ \\
Säntis Tower, Switzerland (present study) & $11.1^{\mathrm{b}}(30)$ & $80(30)$ & $169(30)$ & $0.4(30)$ \\
\hline
\end{tabular}

${ }^{\mathrm{a}}$ The sample size is given in parentheses.

${ }^{\mathrm{b}}$ Pulse peak current, as defined in Zhou et al. [2012] (see Figure 8).

considerably higher than median average currents during the initial stage of upward negative flashes reported by Diendorfer et al. [2009].

[37] The sample of 26 directly measured positive lightning currents analyzed by Berger et al. [1975], commonly used as a primary reference both in lightning research and in lightning protection studies, is apparently based on a mix of (1) discharges initiated as a result of junction between a descending positive leader and an upward connecting negative leader within some tens of meters of the tower top and (2) discharges initiated as a result of a very long (1-2 km) upward negative leader from the tower making contact with an oppositely charged channel inside the cloud [Rakov, 2003]. These two types of positive discharges, which differ by the height above the tower top of the junction between the upward connecting leader and the oppositely charged overhead channel (descending positive leader or positively charged in-cloud discharge channel), are expected to produce very different current waveforms at the tower. Specifically, relatively fast-rising, "microsecond-scale" current waveforms (similar to those produced by negative return strokes in downward lightning) are expected for relatively low junction points, and relatively slow-rising, "millisecondscale" waveforms are expected for relatively high junction points. The microsecond-scale current waveform is probably a result of processes similar to those in downward negative lightning, whereas the millisecond-scale current is likely to be a result of the $M$ component mode of charge transfer to the ground, although in the latter case, current peaks can be considerably higher than for ordinary $M$ components. The microsecond-scale waveforms of Berger et al. have typical risetimes of less than $10 \mu$ s or so. We have not yet observed positive lightning current waveforms of this type. The millisecond-scale waveforms of Berger et al. have typical risetimes of tens to hundreds of microseconds. Our type 1 positive flashes appear to belong to this latter category (see Table 3). These flashes are apparently characterized by an upward negative leader making connection with an already existing positively charged conducting channel in the cloud and can possibly be viewed as positive downward flashes with very long negative upward connecting leaders. In contrast, type 2 positive flashes do not make contact with an existing channel in the cloud and their currents exhibit much slower (more than a millisecond or so) overall risetimes with superimposed fast pulses characteristic of leader steps. The type 2 flashes are "classical" upward discharges.

[38] The impulse charges for type 1 events are presented in Table 3. Note that the impulse charge is defined here as the integral from the $2 \mathrm{kA}$ point on the rising front to the halfpeak value on the tail. The values range from $1.7 \mathrm{C}$ to 32.3 $\mathrm{C}$ with a mean value of $15.6 \mathrm{C}$, which is similar to the median value of $16 \mathrm{C}$ reported by Berger et al. [1975] for the 26 positive flashes discussed above. The latter sample includes both classical downward flashes and those with very long upward connecting leaders. Also presented in Table 3 are the median and geometrical mean values of the peak current, risetime, pulse duration, and action integral, which can be directly compared with Berger et al.'s values. It appears that all the parameters (except for the pulse duration) of our type 1 events are similar to their counterparts reported by Berger et al. [1975].

[39] Cummer and Lyons [2005] examined charge moment changes $(\mathrm{QH})$ in the first $2 \mathrm{~ms}$ after the beginning of the

Table 3. Peak Currents, Impulse Charges (the Integral of the Current From the 2 kA Point on the Front to the Half-Peak Value on the Tail), Risetimes (2 kA to Peak), Pulse Durations (2 kA to 50\% Value on the Tail), Action Integrals, and Charge Moment Changes (Q.H in 2 ms) Assuming a Channel Height of $4 \mathrm{~km}$ for Type 1 Flashes

\begin{tabular}{lccccc}
\hline Flash \# & $\begin{array}{c}\text { Peak Current } \\
(\mathrm{kA})\end{array}$ & $\begin{array}{c}\text { Impulse Charge } \\
(\mathrm{C})^{\mathrm{a}}\end{array}$ & $\begin{array}{c}\text { Risetime } \\
\mathrm{T}_{2 \mathrm{kA}-\mathrm{PEAK}}(\mu \mathrm{s})\end{array}$ & $\begin{array}{c}\text { Pulse Duration } \\
\Delta \mathrm{t}(\mathrm{ms})\end{array}$ & $\begin{array}{c}\text { Action Integral } \\
\left(\times 10^{6} \mathrm{~A}^{2} \mathrm{~s}\right)\end{array}$ \\
\hline 1 & 42.7 & 32.3 & 580 & 1.28 & $\begin{array}{c}\text { Charge Moment Change } \\
\mathrm{Q} \cdot \mathrm{H} \text { in } 2 \mathrm{~ms}(\mathrm{C} \cdot \mathrm{km})\end{array}$ \\
2 & 18.2 & 13.1 & 30 & 1.44 & 1.7 \\
13 & 16.3 & 3.6 & 40 & 0.35 & 0.295 \\
14 & 31.5 & 1.7 & 20 & 0.07 & 0.056 \\
17 & 92.7 & 27.3 & 130 & 0.99 & 0.135 \\
Median & 31.5 & 13.1 & 40 & 0.99 & 4.185 \\
GM & 32.6 & 9.3 & 71.0 & 0.5 & 0.295 \\
\hline
\end{tabular}

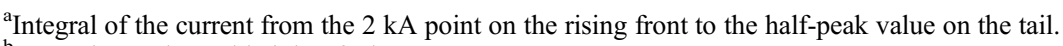

${ }^{\mathrm{b}}$ Assuming a channel height of $4 \mathrm{~km}$.

${ }^{\mathrm{c}}$ Measured from the $2 \mathrm{kA}$ point on the rising front to the half-peak value on the tail. 
return stroke in cloud-to-ground lightning for three night thunderstorms in Colorado, Nebraska, and Kansas High Plains. They found that strokes having charge moments above $600 \mathrm{C} \mathrm{km}$ in two storms and $350 \mathrm{C} \mathrm{km}$ in the other produced sprites after short delays $(<5 \mathrm{~ms})$. (Note that sprites are produced almost exclusively by positive lightning.) $\mathrm{Nag}$ and Rakov [2012], who studied downward positive lightning in Florida, estimated charge moment changes (inferred from measured electric fields and assumed channel length of $12 \mathrm{~km}$ ). Their charge moment changes in $2 \mathrm{~ms}$ varied from 74 to $504 \mathrm{C} \mathrm{km}$, with $16 \%$ (3 out of 19 strokes) having charge moment changes greater than $350 \mathrm{C} \mathrm{km}$. They concluded that it is likely that the majority of their positive return strokes did not produce detectable sprites. We performed a similar analysis for our five type 1 events (assuming a $4 \mathrm{~km}$ channel length) and found charge moment changes in $2 \mathrm{~ms}$ varying from 26 to $157 \mathrm{C} \mathrm{km}$ (see Table 3), all below the $350 \mathrm{C} \mathrm{km}$ "threshold". Thus, it is likely that our positive events did not produce detectable sprites.

\section{Summary}

[40] In this paper, an analysis of the current waveforms of positive flashes recorded on the Säntis tower, Switzerland, from May 2010 through January 2012 is presented. The overall number of recorded flashes was 200, of which 30 were of positive polarity (effectively transported positive charge to ground) and 3 were bipolar. The recorded positive flashes were mainly occurring in the summer months, with August being the month during which most of them were observed (6 events in 2010 and 16 events in 2011). The percentage of positive flashes $(15 \%)$ is considerably larger than in other studies in summer (3\% to $6.5 \%)$.

[41] The observed current waveforms are classified into two types. The first type (comprising 5 flashes out of the measured 30) is characterized by the presence of a large, unipolar main current pulse with a risetime of a few tens of microseconds for four of the five flashes and about $380 \mu \mathrm{s}$ for the fifth one. In four of the five type 1 flashes, the main pulse exhibited structure after its main peak in the form of several subsidiary peaks separated by time intervals of the order of 1 millisecond. The main pulse was preceded, in three of the five flashes, by a clearly discernible initial, slowly rising ramp lasting a few milliseconds, and it was followed by a long steady current with superimposed pulses of both polarities, characteristic of $M$ components. In four of the five flashes of type 1, the main current waveform was preceded by one or several bursts of fast pulses with oscillation frequencies of some $\mathrm{MHz}$, which are presumably due to attempted negative leader processes similar to those observed to occur prior to the formation of a sustained upward positive leader in rocket-triggered lightning.

[42] The second type of observed positive flashes is characterized by a relatively slow waveform with a duration measured in tens of milliseconds with large, oscillatory pulse trains superimposed on the initial rising portion of the waveform. The initial slow pulse is followed by one or more smaller slow pulses superimposed on a steady current and exhibiting rise and fall times of the order of $10 \mathrm{~ms}$ or more. The fast pulses have risetimes of the order of microseconds and are probably associated with upward leader steps. The overall peak current of type 2 flashes is typically associated with one of the fast pulses.

[43] Our data constitute the first direct evidence of $M$ component current pulses of both polarities during steady currents lowering positive charge to ground.

[44] The observed positive flashes (both types combined) are characterized by a median peak current of $11.1 \mathrm{kA}$ and a median flash duration of $80 \mathrm{~ms}$. These values are similar to those based on the data recorded at the Gaisberg tower in Austria. On the other hand, the amount of transferred charge is substantially larger in our data set, with a median value of $169 \mathrm{C}$ (6 times as large as the values obtained at Monte San Salvatore and in Japan and 3 times as large as the value obtained in Austria). Eight flashes out of 30 transported to ground positive charge in excess of $500 \mathrm{C}$.

[45] The parameters of our 5 type 1 events appear to be similar (except for the pulse duration) to their counterparts for 26 positive lightning events examined by Berger et al. [1975], which can be viewed as downward flashes with very long upward connecting leaders. On the other hand, our type 2 events are classical upward flashes.

\section{References}

Berger, K. (1977), The Earth flash, in Lightning, edited by R. H. Golde, pp. 119-190, Academic Press, New York.

Berger, K., R. B. Anderson, and H. Kroninger (1975), Parameters of lightning flashes, Electra. no., 41, 23-37.

Campos, L. Z. S., M. M. F. Saba, O. Pinto Jr., and M. G. Ballarotti (2009), Waveshapes of continuing currents and properties of M-components in natural positive cloud-to-ground lightning, Atmos. Res., 91(2-4), 416-424.

Cooray, V., and H. Pérez (1994), Some features of lightning flashes observed in Sweden, J. Geophys. Res., 99(D5), 10,683-10,688.

Cummer, S. A., and W. A. Lyons (2005), Implications of lightning charge moment changes for sprite initiation, J. Geophys. Res., 110, A04304, doi:10.1029/2004JA010812.

Diendorfer, G., H. Pichler, and M. Mair (2006), Characteristics of positive upward lightning measured on an instrumented tower, paper presented at 28th International Conference on Lightning Protection (ICLP), Kanazawa, Japan.

Diendorfer, G., H. Pichler, and M. Mair (2009), Some parameters of negative upward-initiated lightning to the Gaisberg tower (2000-2007), IEEE Trans. Electromagn. Compat., 51(3), 443-452.

Fleenor, S. A., C. J. Biagi, K. L. Cummins, E. P. Krider, and X.-M. Shao (2009), Characteristics of cloud-to-ground lightning in warm-season thunderstorms in the Central Great Plains, Atmos. Res., 91(2-4), 333-352.

Fuquay, D. (1982), Positive cloud-to-ground lightning in summer thunderstorms, J. Geophys. Res., 87(C9), 7131-7140.

Goto, Y., and K. I. Narita (1995), Electrical characteristics of winter lightning, J. Atmos. Terr. Phys., 57(5), 449-458.

Ishii, M., K. Shimizu, J. Hojo, and K. Shinjo (1998), Termination of multiple-stroke flashes observed by electromagnetic field, paper presented at 24th International Conference on Lightning Protection (ICLP), Birmingham, UK.

Kong, X., X. Qie, and Y. Zhao (2008), Characteristics of downward leader in a positive cloud-to-ground lightning flash observed by high-speed video camera and electric field changes, Geophys. Res. Lett., 35, L05816, doi:10.1029/2007GL032764.

Miki, M., T. Miki, A. Wada, A. Asakawa, Y. Asuka, and N. Honjo (2010), Observation of lightning flashes to wind turbines, paper presented at 30th International Conference on Lightning Protection (ICLP), Cagliari, Italy.

Miyake, K., T. Suzuki, and K. Shinjou (1992), Characteristics of winter lightning current on Japan Sea coast, IEEE Trans. Power Delivery, 7(3), 1450-1456.

Nag, A., and V. A. Rakov (2012), Positive lightning: An overview, new observations, and inferences, J. Geophys. Res., 117, D08109, doi:10.1029/2012JD017545.

Rakov, V. A. (2003), A review of positive and bipolar lightning discharge, Bull. Am. Meteorol. Soc., 84, 767-776.

Rakov, V. A., and M. A. Uman (2003), Lightning: Physics and Effects, Cambridge Univ. Press, New York. 
ROMERO ET AL.: POSITIVE LIGHTNING SÄNTIS TOWER

Romero, C., M. Paolone, F. Rachidi, M. Rubinstein, A. Rubinstein, P. Zweiacker, and C. A. Nucci (2011), Current waveforms associated with positive flashes recorded on the Säntis Tower in summer 2010, paper presented at XI International Symposium on Lightning Protection (SIPDA), Fortaleza, Brazil, October 3-7, 2011.

Romero, C., M. Paolone, M. Rubinstein, F. Rachidi, A. Rubinstein, G. Diendorfer, W. Schulz, B. Daout, A. Kaelin, and P. Zweiacker (2012a), A system for the measurements of lightning currents at the Säntis tower, Electr. Power Syst. Res. J., 82(1), 34-43.

Romero, C., A. Mediano, A. Rubinstein, F. Rachidi, M. Rubinstein, A. Paolone, P. Zweiacker, N. Mora, D. Pavanello, and B. Daout (2012b), Measurement of lightning currents using a combination of Rogowski coils and B-Dot sensors, J.Lightning Res., 4(1), 71-77.

Romero, C., M. Rubinstein, F. Rachidi, M. Paolone, V. A. Rakov, D. Pavanello (2012c), Some characteristics of positive and bipolar lightning flashes recorded on the Säntis Tower in 2010 and 2011,31st International Conference on Lightning Protection (ICLP), Vienna, Austria, September 3-7, 2012.

Romero, C., F. Rachidi, M. Paolone, and M. Rubinstein (2013), Statistical distributions of lightning currents associated with upward-negative flashes based on the data collected at the Säntis tower in 2010 and 2011, IEEE Trans. Power Delivery, 28(3), 1804-1812.
Saba, M. M. F., K. L. Cummins, T. A. Warner, E. P. Krider, L. Z. S. Campos, M. G. Ballarotti, O. Pinto Jr., and S. A. Fleenor (2008), Positive leader characteristics from high-speed video observations, Geophys. Res. Lett., 35, L07802, doi:10.1029/2007GL033000.

Saba, M. M. F., L. Z. S. Campos, E. P. Krider, and O. Pinto Jr. (2009), High-speed video observations of positive ground flashes produced by intracloud lightning, Geophys. Res. Lett., 36, L12811, doi:10.1029/ 2009GL038791.

Saba, M. M. F., W. Schulz, T. A. Warner, L. Z. S. Campos, C. Schumann, E. P. Krider, K. L. Cummins, and R. E. Orville (2010), High-speed video observations of positive lightning flashes to ground, J. Geophys. Res., 115, D24201, doi:10.1029/2010JD014330.

Wada, A., A. Asakawa, and T. Shindo (1996), Characteristics of lightning flash initiated by an upward leader in winter, paper presented at 23rd International Conference on Lightning Protection, Florence, Italy.

Yashunin, S. A., E. A. Mareev, and V. A. Rakov (2007), Are lightning M components capable of initiating sprites and sprite halos?, J. Geophys. Res., 112, D10109, doi:10.1029/2006JD007631.

Zhou, H., G. Diendorfer, R. Thottappillil, H. Pichler, and M. Mair (2012), Characteristics of upward positive lightning flashes initiated from the Gaisberg Tower, J. Geophys. Res., 117, D06110, doi:10.1029/ 2011JD016903. 